Document downloaded from:

http://hdl.handle.net/10251/37990

This paper must be cited as:

Marrakchi, M.; Helali, S.; Soto Camino, J.; González Martínez, MÁ.; Abdelghani, A.; Hamdi, M. (2013). Improvement of a pesticide immunosensor performance using site-directed antibody immobilisation and carbon nanotubes. International Journal of Nanotechnology. 10:496-507. doi:10.1504/IJNT.2013.053519.

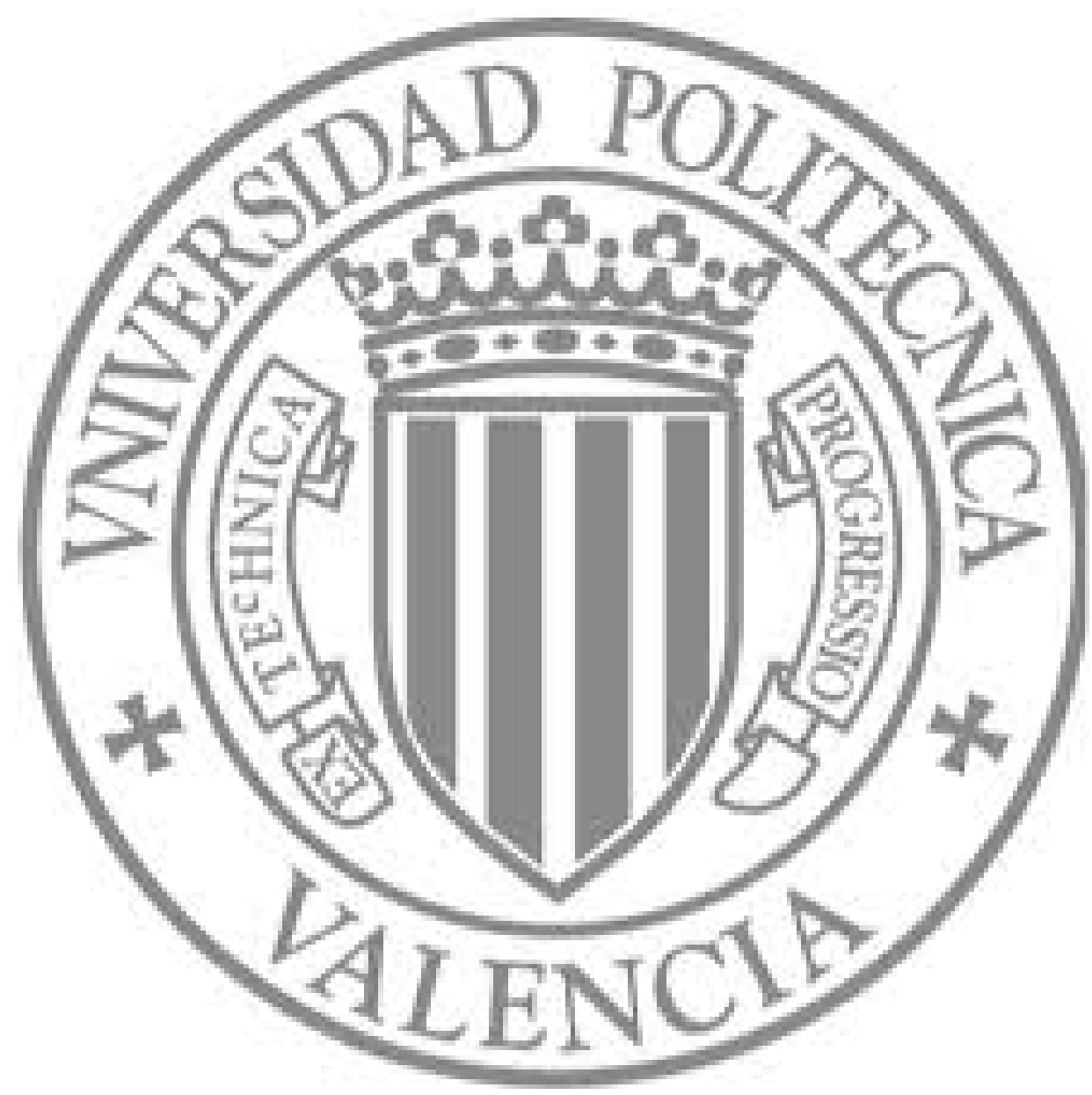

The final publication is available at

http://dx.doi.org/10.1504/IJNT.2013.053519

Copyright Inderscience 


\title{
Improvement of a pesticide immunosensor performance using site-directed antibody immobilization and carbon nanotubes
}

\author{
M. Marrakchi ${ }^{1 *}$, S. Helali², J. Soto Camino ${ }^{3}$, M. \\ A. González-Martínez ${ }^{3}, A$. Abdelghani ${ }^{4}$ and $M$. \\ Hamdi $^{1}$ \\ ${ }^{1}$ Carthage University, Laboratoire d'Ecologie et Technologie Microbienne, INSAT, \\ Centre Urbain Nord, BP676, 1080 Charguia Cedex, Tunisia \\ 2 Research and Technology Centre of Energy, B.P N ${ }^{\circ} 95$ 2050, Hammam Lif, \\ Tunisia \\ ${ }_{3}^{3}$ Departamento de Quimica, Universidad Politecnica de Valencia, Camino de Vera \\ $\mathrm{s} / \mathrm{n}, 46022$ Valencia, Spain \\ ${ }^{4}$ Carthage University, Nanotechnology Laboratory, INSAT, Centre Urbain Nord, \\ 1080 Charguia Cedex, Tunisian Fax: +216 71704329. \\ E-mail:mounamarrakchi@yahoo.fr, salwahleli@yahoo.fr, juansoto@qim.upv.es, \\ mgonzal1@qim.upv.es, aabdelghan@yahoo.fr, moktar.hamdi @insat.rnu.tn \\ *Corresponding author
}

\begin{abstract}
The potential toxicity of pesticide residues in drinking water has meant a rigid regulation for the appearance of these pollutants. Thus, in this work, we developed a new immunosensor for atrazine detection. We focused on the optimization of the antibody immobilization method on sensor surface for the enhancement of the biosensor sensitivity. First, with site-directed immobilization of rabbit anti-atrazine antibodies using goat anti-rabbit immunoglobulin, a detection limit of $0.5 \mathrm{ng} / \mathrm{mL}$ was obtained. This value is 20 times lower than the detection limit obtained with non-oriented antibodies. The second way to improve immunosensor sensitivity consisted of the addition of Carbon nanotubes (CNT). As result of using these CNT, detection limit has been improved again from $0.5 \mathrm{ng} / \mathrm{mL}$ to $100 \mathrm{pg} / \mathrm{mL}$.
\end{abstract}

Keywords: Immununosensor, pesticide, carbon nanotubes, oriented antibody, atrazine

Biographical notes: Mouna MARRAKCHI received her engineer degree in Industrial Biology from the National Institute of Applied Sciences and Technology of Tunis (INSAT) in 2002 and her master's degree of medical and biological engineering from the Claude Bernard University of Lyon in 2003. In december 2006, she obtained her PhD in bioengineering from the Ecole Centale of Lyon. Her research activities deal with the immobilization of different type of bioreceptors, as enzymes, microorganisms and antibodies, for biosensor development.

Saloua HELALI obtained her PhD in physic from the Ecole Centale of Lyon. Now, she is Assistant Professor in Research and Technology Centre of Energy, Tunisia. Her research activities deal with the immobilization of different type of bioreceptors, as polymere, virus and antibodies, for biosensor.

Juan Soto CAMINO graduated in electrochemistry from the University of Valencia in 1986. He is Chemistry Teacher at the Department of Chemistry in Polytechnic University of Valencia, as well as researcher at the Institute of chemistry. 
Miguel Angel González-Martínez graduated in Chemistry at the University of Valencia in 1990. Since November 2000, he is Chemistry Teacher at the Department of Chemistry in Polytechnic University of Valencia, as well as researcher at the Institute of Molecular Recognition and Development.

Adnane Abdelghani is professor in the National Institute of Applied Science and Technology (Tunisia) working mainly on the field of Microsensors and Microsystems. He is the head of nanotechnology laboratory in Tunis.

Moktar HAMDI is professor and the head of Laboratory of Ecology and Microbial Technology in the National Institute of Applied Science and Technology (Tunisia). He has more than 100 international publications and 3 patents in the fields of Environmental Microbiology and Food and Industrial Microbiology.

\section{Introduction}

Pesticides are nowadays considered as common environmental pollutants, although their use is necessary in order to satisfy the food demand of our society. Among the large number of different pesticides, atrazine was the second most frequently detected pesticide in EPA's National Survey of Pesticides in Drinking Water Wells [1]. Thus it is of great significance to accurately quantify the compound at low concentrations. Many analytical applications have been developed for the determination of this compound in environmental samples, the multianalyte residues methods being the most widely used, such as gas chromatography [2], high performance liquid chromatography (HPLC) $[3,4]$, thin layer chromatography [5], and electrophoresis [6,7]. All these methods are very robust and well-established, but in most cases extensive sample pre-treatment including extraction, clean-up and pre-concentration is necessary. Enzyme-linked immunosorbent assay (ELISA) and immunosensing technologies have proved to be fast and sensitive screening methods, as well as quantitative analytical tools useful for pesticide residue determination in food and other matrices. So far, the major drawbacks for the application of pesticide immunoassay in food are related to bad recoveries and the removal of matrix interferences [8]. Immunosensor sensitivity is strongly dependant on the amount of immobilized antibodies and their remaining antigen binding properties. A variety of immobilization methods for proteins has been reported in the literature [9-11], some giving rise to a random orientation of the receptor molecules immobilized on the sensor surface [12]. In a previous work, simple and non time-consuming physical adsorption of specific antibodies on gold [13] was used to develop an immunosensor for atrazine detection [14]. However, oriented immobilization is preferred for maintaining antibody binding properties. This can be achieved, for instance, by using Protein A [15]. Another way to improve immunosensor sensitivity and detection limit is consists of the addition of gold nanoparticles [16, 17], conducting polymer [18, 19], graphene [20] and carbon nanotubes (CNTs) [21-23] to electrode surfaces. Thus, in this study, the following methods were considered: oriented physisorption and carbon nanotubes attachment using carboxylic groups activated with EDC/NHS as a crosslinker. In the two cases, we proposed a new method of insuring the oriented antibody immobilization without the use of protein A. Indeed, we focused on site-directed immobilization of rabbit anti-atrazine antibodies using goat anti-rabbit immunoglobulin. Goat anti-rabbit immunoglobulins recognize specifically FC-region of anti-atrazine antibody which will allow the oriented antibody immobilization on sensor surface. All the steps of the immunosensor buildingup were analyzed via the electro-chemical impedance spectroscopy. 


\section{Experimental methods}

\subsection{Materials and reagents}

Single-walled carbon nanotube-carboxylic acid (SWCNTCOOH) was purchased from Sigma-Aldrich and was used directely without further treatment. Atrazine was from SUPELCO, Bellefonte, PA, USA. Analytical standards of Propazine and terbutylazine were from Dr. Ehrenstorfer (Augsburg, Germany) and Riedel de Haën (SeelzeHannover, Germany). The polyclonal specific anti-atrazine antibody (rabbit polyclonal IgG) was produced in the Universidad Politécnica of Valencia. All other materials, including thiolacid (16-mercaptohexadecanoic acid) (Sigma-Aldrich), Dimethylformamide (DMF) (Aldrich), 1-ethyl-3-(3-(dimethylamino)-propyl) carbodiimide(EDC) (Aldrich), and Nhydroxy succinimide (NHS) (Aldrich) were used as supplied. The buffer solution used in all experiments was phosphate buffer saline (PBS), $\mathrm{pH} 7.2$, containing $140 \mathrm{mM} \mathrm{NaCl}, 2.7$ $\mathrm{mM} \mathrm{KCl}, 0.1 \mathrm{mM} \mathrm{Na} 2 \mathrm{HPO} 4,1.8 \mathrm{mM} \mathrm{KH}_{2} \mathrm{PO}_{4}$. All reagents were of analytical grade.

\subsection{Apparatus}

Cyclic voltammetry (CV) and electrochemical impedance spectroscopy (EIS) were performed with Autolab 302N impedance analyzer (Ecochemie, The Netherlands) and the data was analyzed with the corresponding NOVA1.4 acquisition software.

\subsection{Electrode modification}

\subsubsection{Antibody physisorption}

First, the pretreated electrodes were dipped in the goat anti-rabbit IgG solution (10 $\mu \mathrm{g} / \mathrm{mL}$ in PBS) for $60 \mathrm{~min}$. After this reaction, the surface was rinsed another time with PBS buffer and blocked with BSA $1 \%$ for 30 min. This blockage operation will have the effect of limiting the non-specific adsorption of anti-atrazine antibodies on the electrode surface. The electrode was then thoroughly rinsed with PBS to remove excess of BSA and dipped in the rabbit anti-atrazine antibody (Figure 1(a)).

\subsubsection{Antibody immobilization using carbon nanotube}

The pretreated electrodes were immersed in 11 mercaptoundecanoic acid $1 \mathrm{mM}$ in ethanol solution for $12 \mathrm{~h}$ in order to form a self-assembled monolayer (SAM). The substrates were then rinsed with ethanol in order to remove the unbonded thiols. To convert the terminal carboxylic groups to an active NHS ester, the thiol-modified electrodes were treated with $0.4 \mathrm{mM}$ EDC- $0.1 \mathrm{mM}$ NHS for $1 \mathrm{~h}$. Then, gold electrodes were rinsed with water and dried under nitrogen, $0.3 \mathrm{mg} / \mathrm{ml}$ of SWCNTCOOH were dropped onto the surface for $1 \mathrm{~h}$. The

Figure 1 :Schematic representation of the two immobilization methods. (a) Physisorption of antirabbit followed by Fc-region of anti-atrazine $\mathrm{Ab}$ recognition and his site-directed immobilization. (b) oriented $\mathrm{Ab}$ immobilized on carbon nanotubes (attached using carboxylic groups activated with EDC/NHS as a crosslinker).

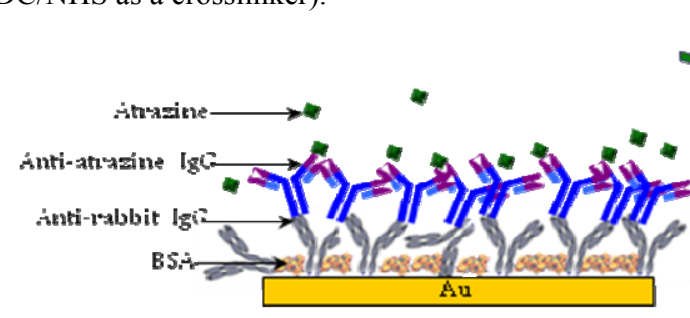

(a)

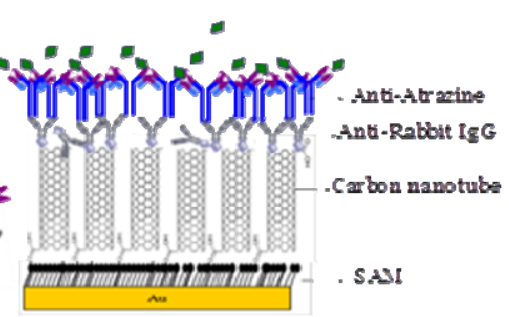

(b) 
excess of SWCNTCOOH were removed by rinsing with DMF. The terminal carboxylic groups in SWCNTCOOH were activated by $0.4 \mathrm{mM}$ EDC- $0.1 \mathrm{mM}$ NHS for $1 \mathrm{~h}$ in order to immobilize the anti-rabbit IgG antibody. Then, the SWCNTCOOH -modified electrodes were treated with $0.1 \%$ BSA for $30 \mathrm{~min}$, to block the unreacted and non-specific sites. Finally, the modified-gold electrode was dipped in the antibody solution $(10 \mu \mathrm{g} / \mathrm{mL}$ in PBS) for $90 \mathrm{~min}$. After rinsing with PBS and water, the electrodes were dried under nitrogen (figure 1 (b)).

\section{Results and discussion}

\subsection{Cyclic voltammetry}

Fig. 2 displays typical cyclic voltammograms of the (i) bore gold, (ii) SWCNTCOOH/Au, Anti-rabbit IgG/ SWCNTCOOH/Au and Anti-atrazine/anti-rabbit $\mathrm{IgG} / \mathrm{SWCNTCOOH} / \mathrm{Au}$ electrode. All voltammograms were cycled five times in order to verify the stability of the signal.

Figure 2: Cyclic voltammograms after different steps of modification: (i) bare gold electrode, (ii) SWCNTCOOH layer modified gold electrode, (iii) SWCNTCOOH covered with anti-rabbit IgG antibody and (iv) immobilization of the anti-atrazine layer. With $100 \mathrm{mVs}-1$ scan rate in a $5 \mathrm{mM}$ $\mathrm{Fe}(\mathrm{CN})-4 /-3$ solution (PBS, $\mathrm{pH} 7.0)$.

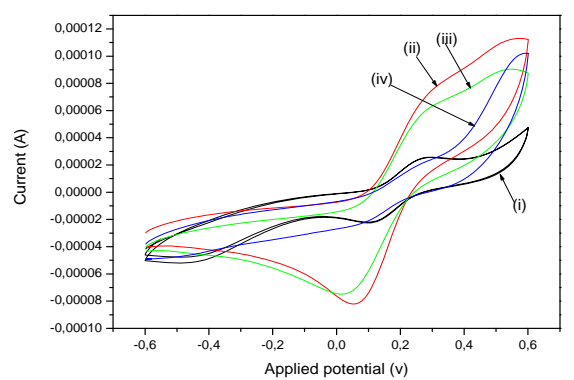

Cyclic voltammograms of the gold electrode (Fig. 2 i) shows a reversible phenomenon, which is the typical behaviour of gold surface with redox couple. The two peaks of the cathodic and anodic waves of redox probe have been obtained. After modification of the gold surface with SWCNTCOOH, the dc-current increases due to the conducting properties of the SWCNTCOOH layer (Fig. 2 ii). After immobilization of anti-rabbit IgG on the SWCNTCOOH layer, the direct current decreases due to the insulating properties of the antibody layer (Fig. 2 iii). The same explanation applies for the decrease of the direct current after specific antibody immobilization (Fig. 2 iv). To confirm all these results, electrochemical impedance spectroscopy measurements were performed on those systems.

\subsection{Electrochemical Impedance Spectra measurements}

The non-faradic impedance measurement was chosen for the detection of atrazine in the present study. Non-Faradic impedance data are often simulated using the modified randles circuit including the two resistive elements, $R_{S}$ and $R_{P}$, and in which the double layer capacitance was replaced by a constant phase element (CPE). $R_{S}$ corresponds to the ohmic resistance of the bulk electrolyte and $\mathrm{R}_{\mathrm{P}}$ to the charge transfer resistance between the solution and the modified electrode surface in the absence of redox species. $R_{p}$ is the diameter of the semi-circle obtained at higher frequencies. CPE takes into account the non-homogeneity of the layer and the impedance of such a non-ideal layer can be 
expressed as $Z(\omega)=\mathrm{k}(\mathrm{j} \omega)^{-\mathrm{n}}$, where $\omega$ is a circular frequency and $\mathrm{n}$ a parameter varying from 0 to $1[24,25]$. The complex impedance can be presented as a combination of the real impedance (Zre) and the imaginary impedance (Zim), Nyquist plot. Typical Nyquist plots for gold electrode, anti-rabbit IgG/Au and Anti-Atrazine/ BSA/ anti-rabbit IgG layer from $50 \mathrm{mHz}$ to $100 \mathrm{kHz}$ are shown in figure $3 \mathrm{a}$.

Figure 3. (a) Nyquist diagram ( $\mathrm{Zr}$ vs. $\mathrm{Zi}$ ) for the impedance measurements corresponding to: (i) Au-electrode; (ii) anti-rabbit IgG/Au electrode and (iii) Anti-Atrazine/ BSA/ anti-rabbit IgG/Au electrode. (b) Nyquist diagram (Zre vs. Zim) for the non-faradic impedance measurements corresponding to (i) SAM modified gold electrode, (ii) SWCNTCOOH functionalized $\mathrm{Au}-$ electrode, (iii) Anti-rabbit IgG/ SWCNTCOOH/Au and (iv) Anti-atrazine/anti-rabbit IgG/ SWCNTCOOH $/ \mathrm{Au}$ electrode. All measurements were performed in PBS $(\mathrm{pH} 7.0)+5 \mathrm{mM}$ $\mathrm{Fe}(\mathrm{CN}) 6-4 /-3$ solution. The amplitude of alternating voltage used was $10 \mathrm{mV}$.

(a)

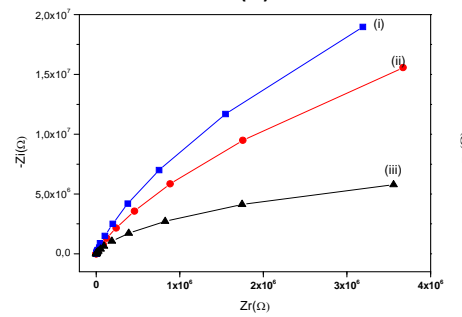

(b)

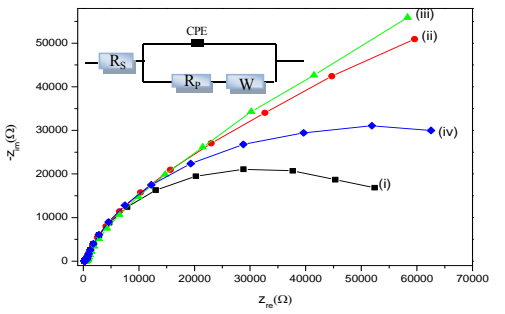

As can be seen in the fitting values reported in Table 1, the charge transfer resistance $(\mathrm{Rp})$ increased after adsorption of antibody rabbit IgG and after immobilization of antiatrazine antibody. This result could be explained by the insulating properties of the fixed layers. Whereas, the gradual decrease in capacitance was related to the positive change in thickness after each immobilization step inside the gold electrode interface and the electrolyte solution. Then, in order to obtain more sensitive electrochemical signals the rabbit IgG antibody was immobilized on gold electrode using SWNT. Figure 3-b showed the EIS of SAM changed gold electrode (curve i), compared with SWCNTCOOH functionalized Au-electrode (curve ii), with Anti-rabbit IgG/ SWCNTCOOH/Au (curve iii) and with Anti-atrazine/anti-rabbit IgG/ SWCNTCOOH/Au electrode (curve iv) in PBS solution. Note that all the spectra are almost similar. Using the equivalent circuit model described in Fig. 3-b, it is possible to fit the impedance spectra. The values

Table 1 Fitting values of the equivalent circuit elements for physical adsorption of anti-rabbit IgG on gold electrode and after binding of anti-atrazine antibody.

\begin{tabular}{lcc}
\hline & Antirabbit IgG & anti-atrazine/ \\
& 18.78 & BSA/anti-rabbit IgG \\
\hline Capacitance, CPE $\left(\mu \mathrm{F} / \mathrm{cm}^{2}\right)$ & 0.946 & 15.804 \\
$\mathrm{n}$ & 184 & 0.959 \\
Resistance, Rs $\left(\Omega \mathrm{cm}^{2}\right)$ & 94.86 & 211.3 \\
Resistance, $\mathrm{RP}\left(\mathrm{M} \Omega \mathrm{cm}^{2}\right)$ & 1365 & 173.4 \\
Resistive Warburg, W1R $\left(\Omega \mathrm{cm}^{2}\right)$ & 0.565 & 11.21 \\
Capacitive Warburg, W1-T $\left(\Omega \mathrm{cm}^{2}\right)$ & 0.478 & 1.97 \\
$\alpha$ & & 0.478 \\
\hline
\end{tabular}


obtained for the constant phase element (CPE) and the charge transfer resistance is shown in the histogram of figure 4, extracted from the computer fitting of each step. It is obvious that the constant phase element at the electrode surface decreases with the positive change in thickness after each immobilization step. Whereas, the addition of CNTs to the SAM modified gold electrode leads to the decrease in the value of the charge transfer resistance $(\mathrm{Rp})$ because of the presence of this conductive. Finally, after each step immobilization, with the addition of rabbit IgG and anti-atrazine antibody the interface resistance increases (decrease in the conductivity due to the insulating properties of grafted layers). In order to test the sensitivity of our constructed biosensor, different

Figure 4. The histogram corresponding to: (A) The constant phase element, CPE, (B) the charge transfer resistance at the electrode upon the stepwise assembly: (i) SAM modified gold electrode, (ii) SWCNTCOOH functionalized Au-electrode, (iii) Anti-rabbit IgG/ SWCNTCOOH/Au and (iv) Anti-atrazine/anti-rabbit IgG/ SWCNTCOOH/Au electrode.
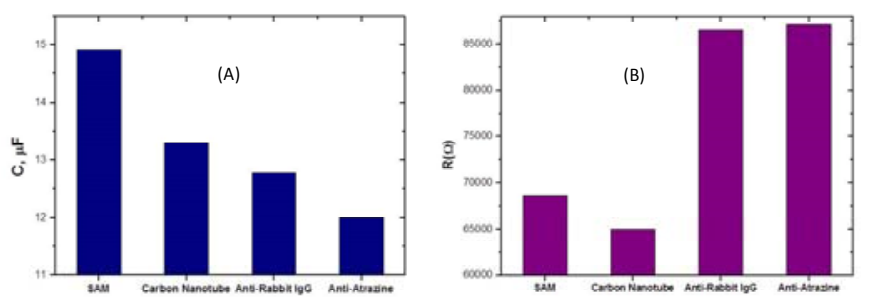

concentrations of atrazine were successively loaded on the anti-atrazine modified electrode. The electrode was dipped into an electrochemical cell containing $5 \mathrm{ml}$ of PBS, $\mathrm{pH}$ 7.2. Antigen-antibody interactions, with different concentrations of atrazine, were monitored by impedance spectroscopy. Different volumes of analyte solution, corresponding to different concentrations of atrazine, were added into electrochemical cell at room temperature. To illustrate the sensitivity of biosensor response to substrate injection, Figure 5, corresponding to the variation of $\log [\mathrm{Z}]-\log \left[\mathrm{Z}_{0}\right]$ at $734 \mathrm{mHz}$ versus atrazine concentration, was plotted (where $[Z]$ is the value of the impedance module of that immuno-functionalized electrode previous to functionalized electrode previous to pesticide addition).

Figure 5. Calibration curves of the variation of impedance at $734 \mathrm{mHz}$ : (a) (i) using physisorption (atrazine concentrations from $500 \mathrm{pg} / \mathrm{mL}$ to $5 \mathrm{ng} / \mathrm{mL}$ ) (ii) using carbon nanotubes (atrazine concentrations from $100 \mathrm{pg} / \mathrm{mL}$ to $1 \mathrm{ng} / \mathrm{mL}$ ) (b) complete calibration curve for atrazine with physisorbed antibodies (atrazine concentrations from $500 \mathrm{pg} / \mathrm{mL}$ to $150 \mathrm{ng} / \mathrm{mL}$ ).

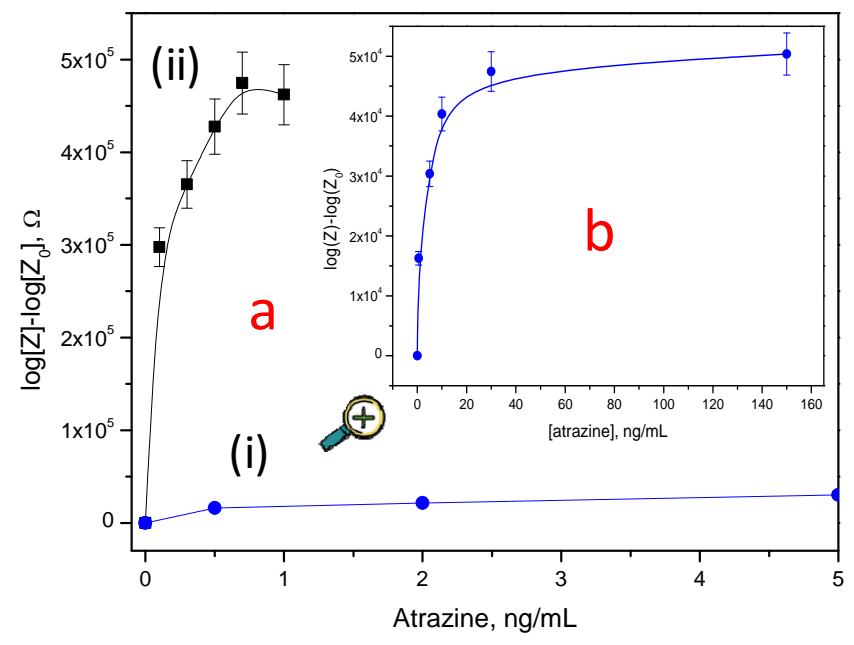


As can be seen in figure 5-b, the immunosensor developed using oriented antibodies for atrazine has a linear shape in the range of 0.5 to $30 \mathrm{ng} / \mathrm{mL}$ with an excellent detection limit of $0.5 \mathrm{ng} / \mathrm{ml}$. When atrazine concentrations became up to $30 \mathrm{ng} / \mathrm{mL}$ the signal tended to saturation. This detection limit of $0.5 \mathrm{ng} / \mathrm{mL}$ is 20 times lower than the detection limit obtained with physical adsorption of non-oriented antibodies [14]. These results are confirming the loss in sensitivity with random antibody immobilization method on sensor surface. On the other hand, when comparing CNT immunosensor (figure 5-a ii) with the sensor non employing carbon nanotubes (figure 5a-i and figure $\mathrm{b}$ (magnification of figure a-i)), response of CNT sensor shows a significant increase. In addition, with CNT the immunosensor detection limit is improved from $0.5 \mathrm{ng} / \mathrm{mL}$ to 100 $\mathrm{pg} / \mathrm{mL}$.

\section{Conclusion}

The oriented antibody immobilization strategy, with site-directed immobilization of rabbit anti-atrazine antibodies using goat anti-rabbit immunoglobulin, has shown its effectiveness in improving the biosensor sensitivity. Indeed, with the same type of immobilization (physical adsorption) the detection limit obtained, with oriented antibodies, was 20 times lower than the one with random physisorption. Moreover, the addition of CNTs to the SAM modified gold electrode has reduced even the detection limit up to $100 \mathrm{pg} / \mathrm{mL}$ which is a thousand times lower than the maximum level allowed by the European Union directive.

\section{Acknowledgements}

This work was financially supported by the PCI cooperation project between Spain and Tunisia.

\section{References}

1 US Environmental Protection Agency (1992), 'National Survey of Pesticides in Drinking Water Walls, Phase II Report', EPA 570/9-91-020. National Technical Information Service, Springfield, VA,

2 Martínez, E., Barcelò, D. (1996), 'The stability of selected herbicides preconcentrated from estuarine river waters on solid-phase extraction disks'. Chromatographia, Vol. 42, pp. 72-77

3 Martín- Esteban A., Fenández P., Cámara C. (1996), 'Breakthrough volumes increased by the addition of salt in the on-line solid-phase extraction and liquid chromatography of pesticides in environmental water' Int. J. Environ. Anal. Chem. Vol. 63, pp. 127 -135.

4 Barcelò, D., Durand, G., Bouvot, V., Nielen, M. (1993), 'Determination of quaternary amine pesticides by thermospray mass spectrometry', Environ. Sci. Technol. Vol. 647, No. 2, pp. 271-277.

5 Zahradnikova, H., Simek, P., Horicova, P., Trinsca, J. (1994), 'Determination of atrazine and simazine in drinking and surface waters by solid-phase extraction and high performance thin layer chromatography', J. Chromatogr. A Vol. 688, No. 1-2, pp. 383-389.

6 Foret, F., Sustacek, V., Bocek, P., (1990), 'Separation of some triazine herbicides and their solvolytic products by capillary zone electrophoresis', Electrophoresis, Vol. 11, No. 1, pp. 9597.

7 Stransky, Z., (1985), 'Isotachophoresis of cationic herbicides in waters and soils', J. Chromatogr. Vol. 320 No. 1, pp. 219-231. 
8 Garces-Garcia, M., Morais, S., Gonzalez-Martinez, M. A., Puchades, R., Maquieira., A., (2004), 'Rapid immunoanalytical method for the determination of atrazine residues in olive oil', Anal. Bioanal. Chem. Vol. 378, No. 2, pp. 484-489

9 Lyn, M., (1978) in 'Immobilized Enzymes, Antigens, Antibodies, and Peptides' (Weetal, H. H., Ed.), pp.12-39, Dekker, New York.

10 Yung-Chuan, L., Chih-Ming, W., Kuang-Pin, H., (2001), 'Comparison of different protein immobilization methods on quartz crystal microbalance surface in flow injection immunoassay', Analytical Biochem. Vol. 299, pp. 130-135.

11 Holford, T.R.J., Davis, F., Higson, S. P.J., (2012), 'Recent trends in antibody based sensors', Biosens. \& Bioelec., Vol. 34, No. 1, pp. 12-24

12 Bonroy, K., Frederix, F., Reekmans, G., Dewolf, E., De Palma, R., Borghs, G., Declerck, P., Goddeeris, B., (2006), 'Comparison of random and oriented immobilisation of antibody fragments on mixed self-assembled monolayers', J. Immunol. Methods, Vol. 312, pp. 167-181

13 Horisberger, M., Vauthey, M., (1984), 'Localization of $\kappa$-casein on thin sections of casein micelles by the gold method', Histochemistry, Vol. 80, No. 1, pp. 9-12

14 Marrakchi, M., Campos-Sánchez, I., Helali, S., Mejri, N., Soto-Camino, J., GonzalezMartinez, M. A., Hamdi, M., Abdelghani, A., (2011), 'A Label-Free Interdigitated Microelectrodes Immunosensor for Pesticide Detection', Sensor Letters, Vol. 9, No. 1-4, pp. 2203-2206.

15 Hirlekar Schmid, A., Stanca, S.E., Thakur, M.S., Ravindranathan Thampi, K., Raman Suri, C., (2006), 'Site-directed antibody immobilization on gold substrate for surface plasmon resonance sensors' Sens. Actuators B, Vol. 113, No. 1, pp. 297-303

16 Morela, A-L., Boujdaya, S., Méthiviera, C., Kraffta, J.-M., Pradiera, C.-M., (2011), 'Biosensors elaborated on gold nanoparticles, a PM-IRRAS characterisation of the IgG binding efficiency', Talanta, Vol. 85, No. 1, pp. 35-42

17 Eguílaz, M., Villalonga, R., Agüí, L., Yáñez-Sedeño, P., Pingarrón, J.M., (2011), 'Gold nanoparticles Poly(diallyldimethylammonium chloride)-carbon nanotubes composites as platforms for the preparation of electrochemical enzyme biosensors: Application to the determination of cholesterol. Journal of Electroanalytical Chemistry, Vol.661, pp. 171-178.

18 Esseghaier, C., Helali, S., Ben Fredj, H., Tlili, A., Abdelghani, A. (2008) 'Polypyrroleneutravidin layer for impedimetric biosensor', Sensors \& Actuators B, Vol. 131, pp. 584-589.

19 Ben Fredja, H., Helali, S., Esseghaier, C., Vonnab, L., Vidalb, L., Abdelghani, A. (2008) 'Labeled magnetic nanoparticles assembly on polypyrrole film for biosensor applications', Talanta, Vol. 75, pp 740-747.

20 Lu, J., Liu, S., Ge S., Y., Mei, Yu, J., Hu, X. (2012) 'Ultrasensitive electrochemical immunosensor based on $\mathrm{Au}$ nanoparticles dotted carbon nanotube-graphene composite and functionalized mesoporous materials', Biosensors and Bioelectronics, Vol.33, No.1, pp.29-35.

21 Weber, J. E., Pillai, S., Ram, M. K., Kumar, A., Singh, S. R., (2011) 'Electrochemical impedance-based DNA sensor using a modified single walled carbon nanotube electrode', Materials Science and Engineering C, Vol. 31, pp. 821-825.

22 Vural, T, Kuralay, F., Bayram, C., Abaci, S., Denkbas, E. B., (2010) 'Preparation and physical/ electrochemical characterization of carbon nanotube-chitosan modified pencil graphite electrode', Applied Surface Science, Vol. 257, No. 2, pp. 622-627

23 Yáñez-Sedeño, P., Pingarrón, J. M., Riu, J., Rius, F. X., (2010) 'Electrochemical sensing based on carbon nanotubes', Trends in Analytical Chemistry, Vol. 29, No. 9, pp. 939-953.

24 Ben Fredj, H., Helali, S., Esseghaier, C., Vonnab, L., Vidalb, L., Abdelghani, A. (2008) 'Labeled magnetic nanoparticles assembly on polypyrrole film for biosensor applications', Talanta, Vol. 75, No. 3, pp. 740-747.

25 Helali, S., Martelet, C., Abdelghani, A., Maaref, M. A., Jaffrezic-Renault N. (2006) 'A disposable immunomagnetic electrochemical sensor based on functionalised magnetic beads on gold surface for the detection of atrazine. Electrochimica Acta. Vol. 51, No. 24, pp. 51825186. 